\title{
THE LANCET.
}

\begin{tabular}{lll}
\hline ToL. II.] LONDON, SATURDAY, MAY 3. & [1827-8. \\
\hline
\end{tabular}

I E C T UR E S

ON THE

\section{THEORY AND PRACTICE OF MIDWIFERY}

DELIVERED AT GUY'S IIOBPITAL BY

DR. BLUN DELL.

\section{Lecture XXVI.}

\section{Of the Extraction of the Fotus by Craniotomy.}

OF all the operations of midwifery, there is none, perhaps, more easily performed, than that of perforation; and many a life, I fear, has fallen a sacrifice to this facility of execution. Of all the operations of our art, however, there is none more dreadful, not to say more awful; for call it embryotomy, craniotomy, or by whatever elegant term you please, in this operation a dagger is struck into the head of an innocent child, often still living, and the brains being reduced to a soft pulp, are suffered to escape at the opening. Mruch evil, and some good, arises, in society, from not calling things by their right names. This practice, however, I am aware, grows out of the nature of man, and cannot be amended. Hellenize then, and Latinize, as much as you please-r' suave sonat," but never suffer a polished and classical appellation to bring before your minds an idea of this operation, divested of that salutary horror with which I conceive it ought ar all times to be contemplated. Dreadful, howerer, as the operation is, the safety of the mother sometimes peremptorily requires its performance; and I here lay before you the severe and formidable instruments by which it is accomplished-the perforator, the crotchet, the craniotomy forceps, of which it is sometimes convenient to have two pair, and the blunt hook, on all which I now proceed to comment, beginning with the consideration of the perforator.

The instrument, which I here exhibit, the perforator, is desigued to be passed

No, zit4. through the child's head by a sort of semirotatory boring action, the same which you would adopt in perforating a piece of board with an awl; the aperture being enlarged afterwards by dilatation, for which purpose the blades, while lying in the opening, are separated from each other. Observe the section on this folded paper. One of the first instruments employed for embryotomic perforation, was a pair of large seissors, recommended by Smellie, and after all, perhaps, if armed with shoulders, as here demonstrated, and committed to cautious and dexterous hands only, it is one of the best contrivances we can employ, for the cutting edge of the scissors has its advantages. Since the time of Smellie, however, the form of the instrument has been modified, the scissory edge having been removed; and I. here show you a specimen of the kind of instrument now received into British practice.

This instrument opens and shuts like scissors, and, like them, is generally formed with a double point. But Mr. Lowdell, of Stamford Street, has, in my opinion, made a considerable improvement in the instrument, and this, too, very simply, by giving it a single point, as here shown, so that it enters the head with more ease and expedition, rendering the operation safer to the mother, and more speedily extinguishing the remains of life in the child. To prevent the blades from entering the cranium too far, about one inch and a quarter from the point, they are formed with a check, or shoulder, beyond which they cannot be pushed.

Some of these instruments are made very light and elegant, qualities of which I do not myself approve. A light perforator is apt to bend in the shank, or break like that on the table ; besides, a roughness of appearance well becumes the austere duties which it is designed to discharge. The instrument I now exhibit, for example, is not thick and strong enough in the shanks, for sometimes you have to open heads which are very firmly ossified; and where that is the case, if the head resists much, there is danger, lest the handles should give way. In choosing a perforator, take care that the joint is very firm, otherwise, when the instrument is in action, disruption and dislocation may oc- 
cur. It is better, too, that the blades at the away. Besides these chisel or scalprifom joint should not touch each other laterally, teeth, there are several which are smaller. in order that no part of the vagina may be designed to give you a hold of the scalp, inclosed and injured there. The instrument To me, however, these smaller teeth appear exhibited will illustrate my meaning. Ex- to be unnecessary, for if you have a good cept the point, all other parts of the instru- hold of the bone, the hold of the scalp, nut ment should be smooth and rounded. "Thou of much importance, will also be securt. shalt do no murder," might, perhaps, with The three large chisel teeth constitute, in great propriety be engraved on the one my opinion, the great excellence of Holmes i blade of the instrument; to the obstetric eulogist, Sir Anthony Carlisle, I commit the choice of a motto for the other blade from the same decalogue.

The next instrument, and which I now hold in my hand, is the craniotomy forceps, of great use in the operation of embriotomy. The ancient accoucheurs were possessed of an instrument called the rostrum anatis, which was, in effect, the craniotomy forceps. In the mutations of fashion, this instrument became obsolete, being super. seded by the crotchet, till it was again introduced by my valued predecessor. After laying ofen the head, Dr. Haighton was accustomed sometimes to make use of a pair of stone forceps, armed with teeth. Dr. Duvis, of George Street, Hanover Square, who has bestowed a great deal of laudable exertion on the subject of instrumental midwifery, has very much improved the ruder instrument of Haighton, not sufficiently powerful in less skilful hands than his own. Here is a very stout pair of forceps of his contrivance, which has, you may perceive, a great number of teeth on one of the biades; these teeth, however, being faulty, because they are too short and delicate, and apt of consequence to bend and wear away under corrosion, becoming thereby unfit to pierce the bones as intended. Corresponding with these dental processes, you have, on the other blade, apertures into which the teeth are received, as in sockets; and thus when the instrument aets as intended, they pass through the bone, giving you a hold sufficiently secure. This instrument, contrived by Haighton, and much improved by Dr. Davis, has been still further perfected by Mr. Holmes of Old Fish Street, a gentleman who, to omit his other instruments, has produced the best pair of craniotomy foreeps that I know of, and which I now always use. You see in his instrument there is no display of elegance, but it is a large, strong, and very powerful implement, not liable, when we are using it, either to bend or break. Of this instrument, the grand perfection lies in the size and strength of the teeth. On one blade there are three large dentiform processes, very like the incisor of a rabbit, if I may be allowed to make such a comparison; and in the other blade are three cavities in apposition with these, into which they pass, after thoroughly piercing the bones, so that there is no danger lest the forceps should slip

There is yet a third instrument, gene. rally used on the Continent, and in this country too, for the extraction of the head after perforation, and which, notwithstad. ing the contrivance of the craniotomy forceps, cannot, perhaps, be rejected from practice altogether, I mean the crotchet. This instrument, of curved shank, furnished with a large handle, and a hooked extre. mity, broad and bluntly pointed, is designed to be employed as a blunt hook externally, or within the head, in the way I shall presently explain.

Nor must I omit to mention, while treat. ing of these instruments, another imple. ment, not frequently required, however; the blunt hook, as it is called, now lying on the table before you. Of this instrument I have to remark, that its shank ought to be strong, its handle large, its shorter arm not longer than necessary, to give a secure hold of the axilla and arm, or any other part on whieh it may be applied. Bluntness is another de. sirable quality, whence its name; a point is useless, and therefore to be condemned.

Our remarks on the different instriments of embryotomy concluded, we will now, if you please, proceed to consider the operation itself, dividing it for the conve. nience of observation, into two varieties, that, I mean, in which the want of room is inconsiderable, and that variety in which we have to act upon a pelvis contracted and distorted in high degree ; and first of craniotomy, in those cases in which the contrac. tion of the pelvis is less considerable.

If the contraction of the pelvis be sliglt, and craniotomy be required, those who are in the habit of using the long forceps will probably have first made trial of this powerful instrument before they have recourse to the destruction of the child; and, if it so happen that the long forceps are still ap. plied to the head at a time when craniotomy is proposed, it will be better still to leave the instrument on the cranium, as its operation may afterwards tend to facilitate both the operation itself and the subsequent $a b$ * straction of the foetus. In such cases, I would recommend you to close the blades of the forceps as forcibly as may be, so as to torpify the feelings by producing a sort of coma, the handles of the forceps being afterwards tied very firmly. This done, in commencing the operation, you take the 
perforator in the right hand, and pass two or three fingers of the left hand up to the sagittal suture, feeling the suture, if possible, and in ordinary cases it may be readly felt. Well, then, conducting the instrument along the fingers, at length you reach the sagittal suture, great care being taken not to touch any other part, and by a semi-rotatory motion you very readily enter the cavity of the cranium. The cranium once entered, without the smallest delay, for the sooner the operation is accomplished the better, lay hold of the two handles of the instrument, and draw them apart from each other, so as to eularge the laceration, a free opening facilitating the operation greatly. ln order to prevent the instrument from escaping when the aperture is dilated, you ought to be very careful, on entering the cranium, to press the blades onward to the shoulders of the instrument, so as to bring these shoulders into contact with the scalp and cranial bones, when there will be no danger of its becoming displaced. In general ( 1 believe) one laceration will lay the head open to a sufficient extent; if, howerer, you are not satisfied with the size of the aperture, you may introduce the instru. ment a second tine, at some little distance from the first opening; and in the same way as before, enlarging by dilatation, you may lay the second opening into the first, forming what is denominated the crucidulaceration. The great object which you seek here is a free opening into the cranium, and, in using the perforator, of this object you should never be forgetful. The head, then, bein' laid open in this manner with all piacticable promptitude, carry your instrument into the brain, and demolish its structure completely, so that if, unlrappily, there be any lite remaining in the child, alf feeling may be destroyed at once. Let the demolition be complete-let the brain be conrerted in to a perfect pulp. Feel what reluctance you may before you begin this terrible operation-the more the betterbut when you have once begun proceed promptly, without flinching-it is too late to look back. In demolishing the brain, it is desirable that you should break up the basis as early as practicable, for this part, I suspect, is more immediately connected with vitality. Cases have happened in which the cranium has been opened, and part of its coutents have been removed, the child coming in to the world alive, to look, as it were, into the face of the operator, and reproach him with his cruel ignorance, or neghyence. The very image of these horrors is rough to make the blood curdle. Never lay the head open, unless there be an absolute netd for it; but when you do, when you must craniotomise, let all your operations be effectually performed.
When in this manuer you have laid open the head and pulpified the brain, it next be? comes your duty to abstract the foetus. This you may sometimes accomplish with the long forceps; the instrument, however, being very liable to become displaced in consèquence of a collapse of the bones, and this more especially if the resistance be considerable. If, however, the difficulty be small, the fotal head may be extracted in this manner without much difficulty; but if the long forceps lose their place, the head not descending, you must then have recourse to the craniotomic forceps already described.

Before you introduce this instrument, $I$ would have you ascertain with care what is the preeise obstacle that precludes the déscent of the head. Generally there is, in these cases, a small distortion of the pelvis ; let this distortion, then, be clearly detected; commonly it lies near the symphysis pubis, or the acetabulum. Frequently, however, there is a mere want of room from before backwards, the symphysis pubis approaching the back of the pelvis, no distortion accompanying. Well, having ascertained the difficulty, slide up the first two fingers of the left hand; and, of these two fingers, place one within the cavity of the cranium and the other on the outside; and then adjusting the instrument with those two fingers, you lay one blade within the head, and the other externally, so as to get the cranial bones between the blades. Before closing the instrument examine very carefully, for you should not proceed with haste here, and satisfy yourselves that no portion of the mother is included between the blades. You had better ask the woman if you occasion pain, for in these easier cases you will give but little uneasiness if you operate neatly; the absènce of pain being a further evidence that you are not including any of the softer parts. Satisfied of this, you then close the blades very firmly, piercing the bones with the dentiform processes of the instrument, so as to render the hold secure. This step of the uperation effected, you then dräw dôwn, co-operating during the pains, if there be any, as these will be found of powerful cooperation. In drawing, too, it is desirable that the tending of the bearing should lie in a line stretching from the umbilicus to the point of the coccyx and the perineum, (great care being taken not to injure this part,) for, when you are bringing the head through the brim, this line may be considered, practically, as representing the axis of the upper part of the pelvis, and you must direct your efforts accordingly. The ordinary craniotomy forceps will frequently slip away; I should, therefore, recommend you to use those improved by Mr. Holmes; even the best contrived instrument may slip; 
bringing along with it the portion of bone to which it is fixed; a grave accident, because the edges and points of this piece of bone, if you are off your guard, may lacerate the passage. When, therefore, you are drawing with the craniotomy forceps, I would further recommend you to lay the fingers of the left hand-all the four-in the vagina, in apposition with the instrument, so that, should the forceps slip, your hand alone may suffer, the woman being protected. For the sake of the patient, and for the sake of your own hand also, I would advise you to abstract with caution, always prompt and in readiness to stop short in your effort should the instrument, or bones, seem disposed to give way. But, to proceed.

You will now and then find the head lying so high in the pelvis, that it is no easy task to apply the instrument in any way over the bones; or if you do obtain a hold, the hold is marginal and imperfect, and the forceps are apt to slip away. Now your better practice here, is to have two pair of forceps, and this number I generally carry with me; and applying your first pair somewhat insecurely, you may still draw the head down a part of the way, though you may not be able to extract it altogether. Having accomplished this, you may then take the second pair of forceps, and drawing the bones down with the first instrument you may bring the bones thoroughly within the gripe of the second pair, obtaining, in this manner, a firmer hold, which may enable you to act with power and effect. When the second pair of forceps has been applied, the first may be taken away.

In using the craniotomic forceps, all these minute points are well worth your attention: get a secure hold of the head with the instrument, and guard against its detachment by slipping; be prepared for the escape of the instrument, whether alone, or with a portion of the bones; draw down during the pains, in order that you may have the full advantage of the co-operation of the uterus; and, above all, take care when you apply the instrument, that you include the parts of the cranium only, and not a part of the mother also-a nicety not always unattended with difficulty, in. asmuch as it is not always easy to distinguish what parts are of the child, and what are of the mother, more especially when the head lies high up.

The craniotomy forceps failing, you may endeavour to abstract the head with another instrument of no small power; and this other instrument is the crotchet, pretty generally known to accoucheurs. Now this instrument, the crotchet, may be applied as formerly demonstrated, either externally or internally; and the latter being the safer, is, on the whole, the better mode. I can- not designate, or mark out to you, any cal particular part of the head, as a bearnz point, on which the instrument may be placed; but I may observe, that passing it into the cranial aperture with the right hand, and guiding it with the left, you may move it about till it fastens on some part either of the basis cranii, or of those bones which form the other parts of the receptacle for the brain. When you have, in this manuer, secured a hold with your crotchet, of course there is always a danger, lest the instrument should slip away either alone, or with part of the bones, and therefore you are to pass your fingers into the vagina be. fore you draw, placing the hand so as receire the point of the instrument if it slip, being continually upon your guard against its slipping, and careful to stop promptly, when you find it disposed to give way. As in using the craniotomy forceps, so here in drawing, let the tendency of your effort be in the axis of the pelvis; ascertain what is the difficulty, if possible, and if there be any uterine pains, take advantage of their co. operation.

Further. In cases where the crotchet does not succeed in withdrawing the bones, there is yet a third expedient to be adopted; and that is, the abstraction of the cranium with the fingers, by means of the scalp and bones. If, as some are, you chance to be strong in the fingers, lay hold of the scalp or skin, which you may find hanging through the pelvis, and by this exert your estractive force. When thus drawn, the scalp, which is sometimes pretty firm, may have the effect of bringing all the bones to. gether; and thus getting them all included within a small compass, you draw down with better success. I have seen an operator succeed in this way, where the craniotomy forceps had been previously tried with little avail. By one or other of these means, then, by the forceps or the crotchet, or the immediate action of the fingers; and especially where there is not much contraction of the pelvis, the head may generally be obstructed, and this frequently with little difficulty. Of these means, the fingers are the safest; and next to these, the forceps ; the crotchet is powerful, but not without its dangers.

In these cases of slighter contraction of the pelvis, I would advise you, as your general practice, always to begin the extraction directly after you have laid open the head, and thoroughly pulpified the brain. Sometimes, however, you will find, on trial of all these modes of abstraction, that still the head will not descend; now what is to be done here? Bleed your patient, if in a state of irritation, according to her strength, to the amount of ten or sixteen ounces ; give her from thirty to sixty drops. ant minims, of the tincture of opium, and 
let her first repose a little, afterwards taking l:tr pains for a few hours; and, at the end of that time, you may find the head inuch lower in the pelvis, and, therefore, to be more easily brought amay. You are not to despair, in this case, as if the delivery nere impracticable. Violence, remember, has no place in scientitic midwifery; if you cannot succeed with gentle efforts, wait to see what nature may accomplish. You may the rather wait for the operations of our common preceptress and auxiliary here; because, when the head has been opened, and the brain has been pulpified and discharged, and the bones are become collapsed; in the general, a heary and dangerous pressure on the softer parts of the mother will cease, and delay, therefore, is not likely to give rise to their fur. ther contusion and mortification.

After the cranium has passed the pelvis with difficulty, we sometimes meet with no small obstruction to the passage of the shoulders, more especially if the pelric bones be more distorted and contracted than ordinary, or if the shoulders be unusually broad. Now this difficulty may be surmounted occasionally, by first laying hold of the remains of the head, and drawing down the shoulders as low as may be, and then, by the action of the fingers, abstracting the arms, a fracture of which is of small importance, as from the previous craniotomy, the child is utterly dead; and thus, in a manner, the arms come through the outlet of the pelvis before the shoulders descend, the difficulty, from the great size of the shoulders, being overcome. If, however, you cannot succeed in an operation of this kind, then you may take the blunt hook here laid on the table before you, (an instrument not often required, though sometimes needful,) and grasping the landle in the right hand, wlile, with the left, you direct it into the asilia, you then, by means of this instrument, draw down the one axilla; afterwards in like manner, fixing it upon the other, and drawing this away, considerable effurt being also sometimes required for this purpose. Should you, however, fail with the blunt hook, the only further effective expedient with which $I$ am acquainted, is the detachment of the arm from the trunk, or the eracuation of the contents of the chest, the blunt hook, or a large perforator, being respectively the instrument best adapted to these operations. In dexterous midwifery, however, it rarely happens that measures of this kind are really required.

When talking of craniotomy, you will hear some practitioners sueak of the abstraction of the brain, and for this purpose a surt of scoup has been contrived, an instru. ment, however, whick I have not hitherto meationed. The truth is, that if you follow the two rules before prescribed-in other words, if you are careful first to make the cranial opening capacious-and, secondly, to pulpify the brain completely, by the craniotomy forceps or crotchet, (for either of these instruments, the crotchet more especially, may be employed for the purpose, ) the brain will, of itself, become discharged at the aperture, and the scoop may be rejected. It is the great glory of British midwifery, that it is, on the whole, simple; and, in general, in obstetrics, the simpler our modes of procedure, the better.

'Thus much then respecting that variety of craniotomy, which is performed in ordinary cases, where there is only a slighter degree of contraction at the brim. All the craniotomic cases, however, be it remembered, are not of this kind. In consultation practice, more especially, you will now and then be called upon to operate, where the pelvis is contracted in a very high degree; so that when the head is laid open, the abstraction. may still be atrended with no small difficulties. Now operating in these cases, in which the pelvis is contracted and distorted in the higher degrees, you must proceed on the general principles already prescribed, only with some little modification. If it is obvious, as it generally will be in those cases, that you must lay open the head at last, I suppose it will be agreed on all hands, that the operation should be early performed, in order that you yourself may be fresh and unexhausted; in order, also, that your patient may not be exhausted, or otherwise injured, before you begin to operate, so as to be worn out with the unavailing efforts of delivery.

A gain, when it is clear you are to lay open the head, you should be careful to open the head very fully, and to pulpify the brain very completely. This is necessary even in ordinary cases, but more especially in those now under consideration, where, unless you have evidently opened the head and fully julpified the brain, you will not have that complete collapse of the bones, so essential to a ready delivery, for parts of the brain will remain in the cavity of the cranium, and room must, of consequence, be lost. The brain then pulpified thoroughly, and the opening into the cranium being made as capacious as may be, you may then proceed directly to the abstraction of the head, taking advantage of pains if there be any. Should you however be unsuccessful in these attempts, then wait for ten or twenty hours if no dangerous symptoms forbid, and under the efforts of the uterus, the remains of the head may be pushed into the inferior parts of the pelvis, more within reach of your extracting instrument.

In all cases, but more especially if there be unusual difficulty, when you are bringing 
away the head, the position in which you place this part is of no small importance; and happily it is by no means difficult, but rather easy to place it in the position most convenient for transmission.

I here exhibit to you the basis of the cranium with its facial bones, the other bones being collapsed in consequence of the abstraction of the brain. To this condition the head is reduced when the cranium is laid open, and its contents are taken away. Now, in a case of this kind, in which the cranial texture is completely destroyed, you may bring down the basis of the cranium parallel with the plane of the brim of the pelvis, in the position which I now demonstrate; but you may observe here, that, in this position, the remains of the head, though small in bulk, still occupy much space in the pelvis. It seems, therefore, that if yau bring down the basis of the scull parallel with the plane of the brim of the pelvis, advantage is lost; a position of the head more favourable, and very important it is that this should be recollected at the bed-side, is that which I now show you. Place the basis of the scull parallel with the posteriof surface of the symphysis pubis, and then, as you may perceive, much less room will be occupied by it. Further, when you place the basis of the scull in this manner, parallel with the symphysis pubis, it is not altogether a matter of indifference which part you draw down, as the most depending, whether the face or the ear, or the occiput of the child, all of which may be brought down in to the most dependent position, the basis of the cranium still, as you perceive, retaining its parallelism with the symphysis pubis. If, for example, you draw down the face as the most depending part, you then, of course, have a simultaneous descent of the neck and occiput ; observe the apparatus; but if the acciput is the part the most dependent, you will then have a combined descent of the face and neck forming together a mass of no inconsiderable bulk. The descent of the ear praduces a sort of intermediate case, into the consideration of which it is unnecessary to enter.

Well, then, it is obvious from these demonstrations, that if the neck and face of the child descend together, the mass transmitted will be larger than that produced by simultaneous descent of the face and occiput, and from all these considerations issues the following rule: when the cranium has been opened, and the brain has been removed, let the basis be laid against the posterior surface of the symphysis, the head being brought down under a presentation of the face, for, in this position, the remains of the cranium will occupy the small. est space in their descent. On the pelvis exlibited, we will illustrate the advantages ar evils of the different modes of descent. In difficult cases, you may facilitate the $d k$. scent, by separately detaching the bones, as much as may be, hefore you bring the heat away; and if you have been waiting some ten or twelve hours after the operation of craniotomy, you may find the parts softened a little by putrescence, and their connexions loosened, so that a detachment may be easily effected, and with the help of the for ceps the bones may be very easily abstracted. Care must be taken not to injure the softer parts, when these bones are taken out.

Such then are the nicer points of this dreadful operation; few, indeed, but of great importance. Though craniotomy must be avoided if possible, yet, if early in the labour, it is perfectly evident that you must open the head; the snoner the operation is performed, the better. After the cranium has been opened, and the brain has been pulpified, if the head do not come away easily, wait for a few hours-ten or twelve for example; then resuming your opera. tions, place the basis of the scull parallel with the symphysis pubis, placing the face below so as to bring forth the head under a facial presentation; and then, if you can get axay the bones separately, remove carefully as many of them as possible; for, in doing this, you not only reduce the bulk of the head, but facilitate greatly the escape of the pulpified brain.

\section{Of the signs which indicate the need of Craniotomy.}

If it be necessary, with caution, to decide in what cases you are to have recourse to the forceps or lever, it is still more necessary to decide with caution, what are the cases in which you may be justified in having recourse to the perforator; and I ad. vise you always duly to investigate the point before you come to your determination, so that, upon reflecting afterwards, you may feel perfectly free from compunction and self-reproach.

By some, perhaps, it might be contended, that we are never justified in having recourse to craniotomy, unless the foetus be already dead, but this opinion is, I con. ceive, erroneous. With the dogmas of the divine, it is not in my province to interfere, and I am glad of it; without, therefore, bab. bling about theology and syringes, I may be permitted to remark, that in British mid. wifery, the life, nay, the preservation of the patient, from the graver lesions of her per. son, is to be looked upon as paramount to every consideration relating to the fotus: and when these require the sacrifice, cro niotomy becomes justifiable. Before this operation is adopted, however, it must be admitted on all hands, that an overpower. 
ing and peremptory necessity, grounded on these conditions, should be clearly established: for I conceire, before the tribunal of reason, this alone can clear the operation from partaking of the nature of murder; and we will, therefore, if you please, proceed to the consideration of those indications by which this necessity is supposed to be demonstreted.

By some, perhaps, it may be contended, that if we have made trial of the forceps or lever, provided we have been unable, with these instruments, to abstract the head, we ought then, without delay, to have recourse to the perforator. To this principle, however, I can by no means accede; for if the accaucheur be prompt, in the administration of the embryospastic instruments, he may sometimes find himself unable to $a b$ stract the head in the morning, although, in the evening, by means of the same instruments, aliving foctus may be brought awaya fact, of which I have myself been an ocular witness in more than one instance. It is clear, therefore, when the tractor or forceps fail you, that the perforator should be had recourse to, provided immediate delivery be necessary.

You may sometimes hear it observed, that the perforator should be used, when the pelvis is contracted in a high degree, and that you onght not to use it, if the aper* tures are of full size; nor is the rule to be al. together neglected. If the pelvis be so contracted, that delivery, without the perfora. tor, is olearly impracticable, then the sooner you employ the instrument the better; but unless the case be extreme, so that the need of the perforator is obvious beyond all doubt, to use the perforator, merely because there is a want of room among the bones, would be a most eriminal rashness. The truth is, that in those cases in which the pelvis is contracted in slighter degree only, you can seldom safely decide respecting the use of the perforator, from the mere measurement of the pelvis; first, because unless much exercised in these inquiries, you may err in the measure; and, secondly, because if the bead be small and soft, and the womb be ac. tive, the fuetus may come away unopened, notwithstanding the deficiency of room. On the whole, therefore, although I would not have you neglect to examine the capacity of the pelvis, yet, unless the contraction be ex. treme, I would recommend you not to rely on this measurement, in deciding whether you ought or not to have recourse to the perforator. In his work upon midwifery, Capuron relates two cases, in one of which the pelris measured only three inches between the front and back, in the other, not more than two inches and a half, the full ca. pacsty in a well formed pelvis being of four incles. Both these women, however, as
Capuron relates the story, became the mothers of living children; and, from the whole account, we may draw this useful information-I mean, that we must never rashly condemn the foetus, merely because the pelvis of the mother is contracted ; the fact indeed ought to influence our judgment, but certainly ought not alone to determine it.

Further, you are not justified in laying open the bead merely because, in previous labours, the operation has been performed, and that too repeatedly. Suppose, for example, five or six fotuses have all been destroyed in previous labours, the pelvis being confessedly narrow. A fact of this kind coustitutes, no doubt, a presumptive evidence, that the operation may be again necessary, but the proof is not decisive; nor are you, therefore, justified in making use of the perforator, unless some strongef reason can be given. Various circum. stances, in any given delivery afterwards, may facilitate parturition. The labour may be premature, or though of full age, the fœtus may be softer, or much smallex than ordinary, and it may yield of consequence to the forceps or tractor, or even to the unas. sisted efforts of the uterus; so that, on all these accounts, it would be highly criminal to perforate, merely because the operation had been performed repeatedly on the same woman before.

Some praetitioners, with laudable huma. nity, have maintained, that perforation ought not to be performed unless we have proof that the foetus is dead in utero; and $I$ do believe, that in many instances, it is not necessary to lay the head open till the foetus have been subjected to so much compression from the action of the uterus that its vitality is become extinct. Unhappily, how. ever, even if we accede to this rule, it will not be found of easy application, as we are not always able to decide, with absolute certainty, whether the child is dead or not. From the symptoms which $I$ shall presently state, we may, indeed, sometimes ascertain the fact with a high degree of probability: but it often happens, that the child is dead without our knowledge, and frequently, when the fotus has been pronounced to be dead, it manifests the signs of vigorous life, as soon as it has quitted the vagina. Should we, therefore, grant to the speculator, that the indication for the use of the perforator may be taken from the death of the child, we must still maintain that, in practice, the rule is exceedingly defective, inasmuch as it necessarily partakes of all that uncertainty which belongs to those symptoms by which the death of the foetus is supposed to be indicated. Not, however, to weary you with the critical enumerations of indications for the use of the perforator, of which I do not 
approve, 1 will now lay before you those which 1 employ in my own practice.

Betore the perforator is used, I endeavour to be fully satisfied that the security of the life or person of the patient peremptorily requires the delivery; and I consider that the security of the patient demands delivery, with that degree of certainty which makes it our duty to operate, provided the head have made little or no advance, altbough the woman have been in active labour for sixand-thirty or eight-and-forty hours after the discharge of the waters; or provided, moreover, however short the labour, the symptoms of danger or damage, enumerated in a former lecture, and to be relieved effectually by delivery only, are beginning to make their appearance.

Again : satisfied that the perforator is ne. cessary, I endearour further to ascertain that the delivery is not to be accomplished either by the embryospastic instruments or the Cxsarian incisions. If the delivery must at last be effected by the Casarian incisions, it must be admitted, on all hands, that craniotomy is unjustifiable, and I shall endeavour, hereafter, to lay down the principles by which we may determine this point. If the delivery may be safely accomplished without our embryotomic operations, by the mere use of the embryospastic instruments-the tractor, I mean, or forcepsthen of course, although the fatus in these difficulties is frequently still-born after all, to craniotomise would be unjustifiable. The safety and practicability of delivery by the forceps or the tractor, in any given case, must depend, not only on the conditions of the delivery, but the dexterity of the operator; and, perhaps, the only certain method of determination in dubious cases, must be taken from our making the essay-gently, dexteronsly, resolutely, yet cautiously, and with great care, lest we should lacerate or contuse. Well, then, suppose delivery by the Crsarian incisions to be unnecessary, and by the embryospastic instruments impracticable-suppose, moreover, that the safety of the life, or person of the patient, demand immediate delivery with that degree of certainty on which, in surgery, it is reasonable to act. Under these conditions, it seems to me, that we have made out a clear need for the perforator, and however revolting the operation may be, craniotomy becomes justifiable. Before you open the head, have a second opinion-this is a good check upon temerity; the former need of the operation, the contraction of the brim of the pelvis, and the death of the fotus, may all be allowed to exert some influence over your decision ; but, be it remembered, that from these considerations alone, your determination must not in general be taken.

\section{LECTURES ON CHEMISTRY,}

BY

\section{PROFESSOR BRANDE.} Delivered at the Royal Institution of Great
Brituin.

InCTURE XXXIX.

On Arsenic, Molybdenum, Chrome, Tungsten, Columbium, and Nickel.

$I_{\mathbf{T}}$ happens, Gentlemen, with arsenic, as with most other poisons when taken into the stomach, that it occasions romiting, and it is no uncommon thing to find persons killed by arsenic, and yet be unable to detect the smallest portion of it after death in the stomach or bowels; this is continually happening; and as you cannot, from the ap. pearances after death, or from the symp. toms, certainly determine the nature of the poison used, it becomes requisite to be very careful to collect these portions of matter thrown off by the stomach, in which the arsenic is supposed to be contained. You find that pain, and a sensation of burning throughout the alimentary canal, are complained of by persons who have taken arse. nic; but these, although the leading symp. toms, would not enable you to determine whether arsenic had been taken or not. This burning sensation throughout the stomacl and bowels, is followed by vomiting and purging, and generally there is a quantity of bloody mucus thrown off from the stomach, indicating the degree of irritation going on. Drinks of all kinds are rejected by the stomach, and after a time the person suffers from fainting fits, great thirst, and intense heat of the skin; the pulse becomes small and irregular, and there are violent palpitations and cramps in different parts of the body, especially in the extremities; cold sweats supervene, and an eruption of red and purple spots upon the skin precedes the fatal termination of the case. Delirium is not an usual consequence of poisoning by arsenic, and serves as one of the distinctions from cases of poisoning by opium and other narcotic poisons. The mind is usually cleat in cases where arsenic has been taken, almost to the last. After death, all that is found is an inflammatory state of the sto* mach, red patches of inflammation being found upon its inner or mucous coat, and if you pass your finger over them, and rub of the mucus and coagulable lymph effused, you will find the parts beneath intensely red, usually terminating abruptly at a given point ; it also generally happens, I believe, that the blood in the large vessels is found in a fluid state, not coagulated, as it commonly is, after death. 